\title{
Recent changes in salt use and stroke mortality in England and Wales. Any help for the salt-hypertension debate?
}

\author{
RICHARD O CUMMINS*
}

From the Department of Clinical Epidemiology and General Practice, Royal Free Hospital School of Medicine; London NW3 2PF, UK, and University Hospital, Emergency Medicine Service, RC-02 Seattle, Washington 98195, USA†

ABSTRACT This analysis attempts to fill the gap in the epidemiological evidence about the relation between dietary salt and hypertension. Changes in the purchase of salt in England and Wales are compared with changes in mortality from cerebrovascular disease (1958-78). Stroke mortality, a major sequel of hypertension, has declined in this period. Consumer purchases of salt have decreased also, as suggested by the National Food Survey. While these trends are consistent with the salt-hypertension hypothesis, the picture is confused by an increase in meals eaten outside the home, by the consumption of more processed food, and by a higher prevalence of refrigerators. Other events, such as medical,treatment of hypertension or changes in the case fatality rate, could have contributed to the decline in stroke mortality. This secular trend analysis, using available data, does not clarify the salt-hypertension debate.

The debate over the role of salt in the aetiology of hypertension continues in medical journals. ${ }^{1-6}$ Various types of studies have presented evidence for this argument, including between-population comparisons, ${ }^{78}$ within-population comparisons, ${ }^{910}$ intervention projects, ${ }^{11}{ }^{12}$ and experiments in man $^{13} 14$ and animals. ${ }^{15}$ Missing from these studies, however, is a time trend analysis; a secular trend analysis is an unsophisticated method, most often used to generate hypotheses, ${ }^{16}$ but it may be helpful if it contributes to the coherence and consistency of evidence collected about a causal hypothesis.

This study reports data on changes in salt purchases in England and Wales, and compares these changes with trends in cerebrovascular mortality (1958-78). If excessive consumption of salt increases the incidence of hypertension then changes in the use of salt could lead to parallel changes in strokes, which are the major sequel of hypertension.

\section{Materials and methods}

SALT PURCHASES

Information was obtained from yearly volumes
(1958-78) of the National Food Survey. ${ }^{17}$ Housewives are asked to record all food purchased for home use. A random sampling frame, based on addresses within polling districts, is used; it averages $6000-8000$ households a year. In 1958 table salt was first entered as a separate item. It is not known if food purchases recorded in the National Food Survey are actually consumed.

From the National Food Survey tables (ounces of food/head a week) all items were selected that were (a) consistently reported from 1958 to 1978 , and (b) listed as high sodium items in standard nutrition books. ${ }^{18}$ Fifteen items met these criteria and are listed in the legend to the table. An estimate of sodium consumption from these 15 items was calculated from conversion values in the fourth edition of McCance and Widdowson's The Composition of Foods. ${ }^{19}$ When McCance and Widdowson gave a range of sodium content for a food, the midpoint of the range became the conversion value. The sodium content of these food items was assumed to be constant between 1958 and 1978.

\footnotetext{
*Milbank Memorial Fund Scholar, and assistant professor of medicine, University of Washington, Seattle, Washington. 
CEREBROVASCULAR MORTALITY

The Registrar General's Statistical review of England and Wales supplied data on mortality from cerebrovascular disease for 1958-78.20 The International Classification of Disease codes 330-334 (vascular lesions of the central nervous system; seventh revision, 1958-67) and 430-438 (cerebrovascular disease; eighth revision, 1968-78) were used to prepare this report.

\section{Results}

\section{SALT/SODIUM PURCHASES}

The table presents data from the National Food Survey on the actual grams of sodium purchased/person a week. ${ }^{17}$ Sodium, rather than salt, is tabulated because these food items may contain sodium nitrate and sodium nitrite, the leavening agents baking powder and baking soda, which contain sodium, and the artificial sweetener sodium saccharin. Table salt has been the greatest single source of sodium in the National Food Survey; it contributes $35-40 \%$ of the sodium from these items. "Total bread" products are also important, contributing $25-30 \%$ of the sodium consumed from these items.

The figure displays the 1958-78 trend in the consumption of sodium for the total 15 items. A gradual decrease of about $15-20 \%$ has occurred in the consumption of sodium from these items. A decrease in bread consumption explains most of this decline (table). Bread is both moderately high in sodium (about $153 \mathrm{mg}$ sodium/ounce) and eaten in large amounts. In the 1958 National Food Survey 47 ounces of bread were purchased/person a week; by 1978 this had declined to 32 ounces.

Trends in salt purchases are erratic, dependent on winter weather, when salt is used to de-ice domestic footpaths, and on market conditions. The unusual increase in purchases of sodium in 1974 was due to panic buying of salt after widespread rumours of a shortage-rumours that, the National Food Survey observed, "the housewives failed to take with a pinch of salt." The decline in salt purchased in 1975 resulted from use of supplies stockpiled in 1974.

\section{CEREBROVASCULAR DISFASE MORTALITY}

The table presents the number of deaths per 100000 for men and women aged $65-74,{ }^{20}$ the age group that accounts for most deaths from stroke. The figure presents these data graphically. For both men and women a $25-35 \%$ decline in mortality rates occurred in these two decades.
TRENDS IN SODIUM PURCHASES AND CEREBROVASCULAR DISEASE MORTALITY

Both sodium purchases and stroke mortality for men and women decline, more or less in parallel, from 1958 (figure). This positive association between potential sodium consumption and stroke mortality is consistent with the salt-hypertension hypothesis.

Sodium source (g/person a week) and cerebrovascular disease mortality (deaths/100 000, men and women, aged 65-74). 1958 to 1978

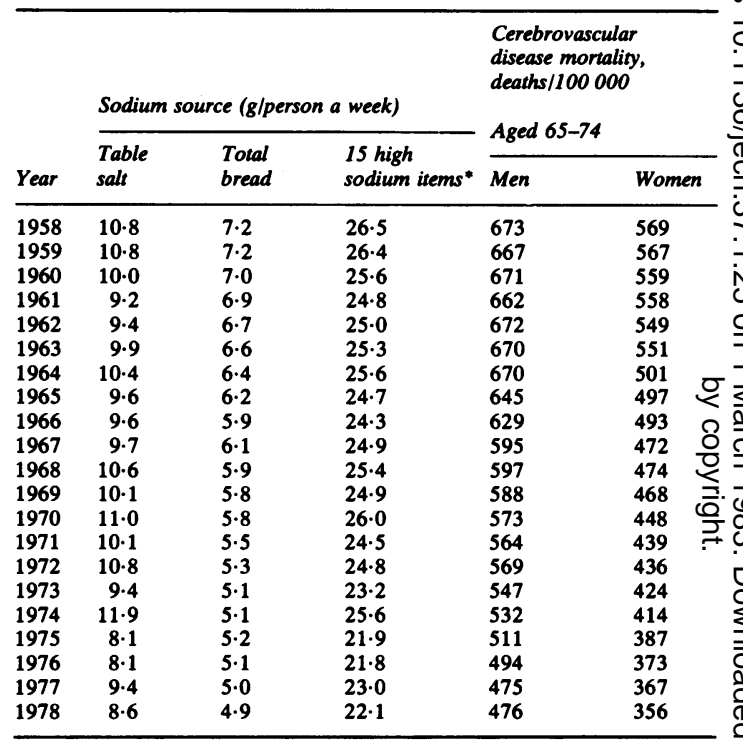

* Includes table salt plus total bread, as well as: total cheese, bacon and ham (uncooked), sausages (uncooked, pork), sausages (uncooked, beef), butter, margarine, canned peas, canned beans, biscuits, breakfast cereals, canned soup, potatoes (old, new, chips, crisps), total liquid milk.

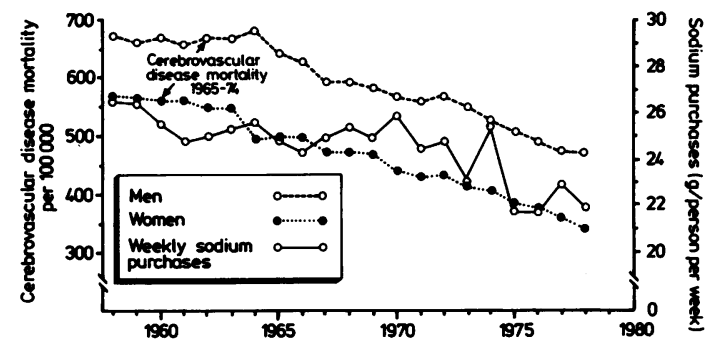

Cerebrovascular disease mortality (deaths/100 000, men and women aged 65-74) and sodium purchases (g/person a week); $1958-78$. 


\section{Discussion}

\section{SALT PRODUCTION}

Salt produced for human consumption is just one product of a diverse industry in England and Wales. Only $5 \%$ of the national production goes into food processing; $20 \%$ is devoted to industrial and chemical processes, exports, and agriculture; and $55 \%$ is converted into inorganic chemicals. Rock salt, used mainly in maintaining roads in winter comprises the other $20 \% .{ }^{2122}$

Processed foods provide roughly half the daily sodium intake. ${ }^{23}{ }^{24}$ All items listed in the legend to the table are considered processed or manufactured foods. Various reasons explain the prominence of salt in such foods. Firstly, salt is a popular and ancient flavour enhancer. It is a preservative for processed meats and helps cure fermented foods. In the production of cheese it affects texture and controls aging. In baked goods it stops yeast activity and enhances dough characteristics.

\section{SODIUM CONSUMPTION}

The data from the National Food Survey (table and figure) display a gradual decline in potential sodium intake from 15 high sodium items, mostly due to a decline in the amount of bread people eat. Does consumption of sodium for these 15 items accurately reflect overall consumption of sodium? Possibly. The sodium content of all items in the National Food Survey was totalled by Bull and Buss for $1978 .{ }^{23}$ Their figure of $3.84 \mathrm{~g}$ of sodium/person a day $(2.60 \mathrm{~g}$ from food and $1.24 \mathrm{~g}$ from table salt) is reasonably close to the figure of $3.2 \mathrm{~g}$ derived from the 15 items in this study. This suggests that most sodium consumed in the National Food Survey comes from these selected high sodium items.

Other estimates of average daily sodium consumption are higher than this study-for example, the British Nutrition Foundation calculated a range of $4 \cdot 5-5 \cdot 2 \mathrm{~g} .{ }^{25}$ This study, as a time trend analysis, required food items of a high sodium content that were consistently recorded for 21 years in the National Food Survey. Since only 15 items met these requirements, the average estimate of $3.5 \mathrm{~g}$ sodium/person a day falls short of a total dietary sodium estimate.

A problem with the National Food Survey is that it records food and table salt purchases rather than actual consumption. Unknown amounts of table salt go to homemade cleaning and pickling solutions, ice-covered steps and pavements, home water-softeners, and art projects. Again, the National Food Survey does not include the large amount of sodium eaten outside the home, estimated at one meal in four for working adults. ${ }^{26}{ }^{27}$ Often these meals consist of highly processed "convenience" or "fast" foods that are heavily loaded with salt. Consumption of these foods is increasing: the National Food Survey observed an $88 \%$ increase in average expenditures for convenience foods in the five-year period 1971-5.17

The percentage of homes owning a refrigerator has increased continually, from $33 \%$ in 1962 to $94 \%$ in 1978. ${ }^{17}$ Experts have argued that this increase in refrigerators made salt preservation of food superfluous. As a result, salt intake decreased, blood pressures declined, and lower stroke mortality followed. ${ }^{28} 29$ This argument is difficult to evaluate. Belgian researchers, however, document a 50\% decline in mean 24-hour sodium excretion in subjects studied between 1966 and 1979, and suggest increased use of refrigerators as an explanation. ${ }^{28} 29$

While the trends in the figure suggest a relationship between salt use and stroke mortality, the data are too weak to support any firm conclusions. It is not clear whether salt intake has been increasing or decreasing: national salt production, which has increased, cannot be broken down to salt destined only for human consumption; high sodium foods in the home appear to have declined, according to the National Food Survey; and more refrigerators have decreased the need for salt preservation of food. In contrast, the intake of highly salted convenience and processed foods has imposed a greater sodium load over the years, as has the increased percentage of meals eaten outside the home. None of these changes over time can be quantified accurately.

Stroke mortality was used in this analysis because it is the major manner by which hypertension produces death, and because mortality data for cerebrovascular disease are more accurate than available data for hypertension. It is not clear why the decline in strokes has occurred; a decrease in blood pressure is only one of several possible explanations. ${ }^{30}$ Change in diagnostic fashions, for example, or a decrease in the stroke fatality rate could produce an apparent decrease in stroke mortality while the true incidence of disease remained constant or increased. A decline in the major stroke risk factor, raised blood pressure, may have resulted from increased use of antihypertensive agents. The decline in cerebrovascular disease, however, started before the widespread marketing of these medications and has occurred in age and sex groups seldom prescribed the drugs..$^{30}$

As a time-trend analysis, this study attempts to fill a gap in the epidemiological evidence marshalled for the salt-hypertension debate. It presents data that are limited and cannot confirm or invalidate the salt-hypertension hypothesis. In the future better 
monitoring of sodium consumption, such as sodium content labels on processed foods, could provide valuable information and help settle the controversy.

Drs R D Moorhouse and A B Whitehead of the Salt Manufacturers' Association and Imperial Chemical Industries and Mr Edward Druce, Dr P J Harries, and Laura Cousins, of RHM Foods Ltd, provided valuable information on salt production and use in England and Wales. Miss Jean Marr provided nutritional advice, critical commentary, and access to her complete collection of the National Food Survey. Professors Geoffrey Rose and A G Shaper contributed encouragement and critical commentary.

\section{References}

${ }^{1}$ Anonymous. New evidence linking salt and hypertension. Br Med J 1981; 282: 1993-4.

${ }^{2}$ Swales JD. Dietary salt and hypertension. Lancet 1980; i: 1177-9.

${ }^{3}$ Anonymous. Hypertension-salt poisoning? Lancet 1978; i: 1126-7.

${ }^{4}$ Tobian L. Dietary salt (sodium) and hypertension. Am J Clin Nutr 1979; 32: 2059-662.

${ }^{5}$ Wilhelmson L. Salt and hypertension. Clinical Science 1979; 57: 4555-88.

${ }^{6}$ Simpson FO. Salt and hypertension: a sceptical review of the evidence. Clin Science 1979; 57: 4635-805.

${ }^{7}$ Gleibermann L. Blood pressure and dietary salt in human populations. Ecology of Food and Nutrition 1973; 2: 143-56.

${ }^{8}$ Page LB, Damon A, Moellering RC. Antecedents of cardiovascular disease in six Solomon Islands societies. Circulation 1974; 49: 1132-46.

${ }^{\circ}$ Beevers DG. Hawthorne WM, Padfield PL. Salt and blood pressure in Scotland. Br Med J 1980; 281: 641-2.

${ }^{10}$ Miall WE. Follow-up study of arterial pressure in the population of a Welsh mining valley. $\mathrm{Br} M e d J$ 1959; ii: 1204.

${ }^{11}$ Medical Research Council. The rice diet in the treatment of hypertension. Lancet 1950; ii: 509-13.

${ }^{12}$ Morgan $T$. Effect of reduction in salt intake on hypertension. Am Heart J 1979; 97: 811-2.
${ }^{13}$ Garay RP, Meyer P. A new test showing abnormal $\mathrm{Na}^{+}$ and $\mathrm{K}^{+}$fluxes in erythrocytes of essential hypertensive patients. Lancet 1979; i: 349-53.

${ }^{14}$ Poston L, Sewell RB, Wilkinson SP, et al. Evidence for a circulating sodium transport inhibitor in essential hypertension. Br Med J 1981; 282: 847-9.

${ }^{15}$ Dahl LK, Schackow E. Effects of chronic excess salt ingestion: experimental hypertension in the rat. Can Med Assoc J 1964; 90: 155-60.

${ }^{16}$ MacMahon B, Pugh TF. Epidemiology: principles and methods. Boston; Little, Brown and Company, 1970: 163.

${ }^{17}$ Ministry of Agriculture, Fisheries, and food. Domestic food consumption and expenditure: 1958-1964; and Household food consumption and expenditure: 1965-78. Reports of the National Food Survey Committee. London; HMSO.

${ }^{18}$ Davidson S, Passmore R, Brock JF, Truswell AS. Human nutrition and dietetics. 6th ed. London: Churchill Livingstone, 1975: 100.

${ }^{19}$ Paul AA, Southgate DAT. McCance and Widdowson's the composition of foods. 4th ed. Oxford: Elsevier Biomedical Press, 1978.

${ }^{20}$ General Register Office. The Registrar General's statistical review of England and Wales for the years (1958-1978). Part 1; tables, medical. London: HMSO, 1958-78.

${ }^{21}$ Institute of Geological Sciences. Mineral Resources Consultative Committee. Mineral dossier No 7. Salt. Northold AJG, Highley DE, compilers. London: HMSO, 1973.

${ }^{22}$ Meynadier J. The development of the salt market in Western Europe. European Committee for the study of salt. Fifth International Symposium on Salt. Hamburg, 1978.

${ }^{23}$ Bull NL, Buss DH. Contributions of foods to sodiume intakes. Proc Nutr Soc 1980; 39: 30A.

${ }^{24}$ Buss DH, Lindsay DG. Reorganisation of the UK total diet study for monitoring minor constituents of food. Food Cosmet Toxicol 1978; 16: 597-600.

${ }^{25}$ British Nutrition Foundation. Salt in the diet. (Briefing paper No 2.) London: British Nutrition Foundation; June, 1981.

${ }^{28}$ Hosking M. Salt and hypertension. Med J Aust. 1979; 2: 351-2.

${ }^{27}$ Dale NE. Sodium and potassium content of some Australian foods and beverages. Med J Aust 1979; 2: 354-5.

${ }^{28}$ Joossens JV, Willems, J, Claessens J, et al. Sodium and hypertension. In: Nutrition and cardiovascular diseases. Rome: Morgagni Edizi oni Scientifiche, 1970: 91-110.

${ }^{28}$ Joossens JV, Kesteloot H, Amery A. Salt intake and mortality from stroke. $N$ Engl J Med 1979; 300: 1396.

${ }^{30}$ Barker DJP, Rose G. Epidemiology in medical practice. 2nd ed. London: Churchill Livingstone, 1979. 